\title{
A NOTE ON THE ANAEMIAS OF PREGNANCY
}

BY

G. D. KERSLEY, M.D.Cantab., M.R.C.P.Lond. ASSISTANT PHYSICIAN, ROYAL UNITED hOSPITAL, BATH

AND

D. A. MITCHELL, M.D., F.R.C.S.Ed., M.C.O.G. GYNAECOLOGIST, ROYAL UNITED HOSPITAL, BATH

Much has been learnt during the last few years about both pernicious anaemia and the simple achlorhydric microcytic anaemias described by Witts, but, although Whitby, in 1932, wrote a paper on "Anaemias in Pregnancy," the practical importance of these anaemias has been insufficiently realized. The reason for this is not far to seek, because the onset is so insidious and the symptoms are usually ascribed to the pregnancy. The result is that a really dangerous degree of anaemia, most frequently of the microcytic type, arises without its presence being even suspected, and if such a case comes untreated into labour the danger of obstetric shock, even in the absence of any blood loss, is very great.

Some slight diminution in the haemoglobin content and red cell count of the blood is physiological during pregnancy on account of hydraemia, but in addition to this there is very often a superadded true anaemia. The common anaemias of pregnancy are the simple types which may occur apart from pregnancy, but their onset is masked and their gravity accentuated by the drain of the foetus on the maternal organism, particularly in the latter third of gestation. They may thus be subdivided into five kinds: the common microcytic type, the more rare megalocytic or pernicious type, anaemia due to haemorrhage, anaemia due to haemolysis following sepsis, and lastly the rare acute idiopathic haemolytic anaemia of pregnancy.

\section{Microcytic Anaemias}

The microcytic anaemias arise from a break in the erythron, or chain of red cell development, at the level of the normoblast owing to lack of iron. This may be due to one or more of three factors-deficiency of iron in the food, deficient absorption, and excessive utilization. Deficient absorption is mainly due to the observed fact that throughout pregnancy there is a reduction of the secretions of the stomach, including the hydrochloric acid content. Strauss and Castle found that in 75 per cent. of cases there was hypochlorhydria during pregnancy with immediate recovery in the puerperium. The remaining 25 per cent., with normal stomach contents in pregnancy, showed a puerperal hyperchlorhydria. The effect of excessive utilization is seen in the last three months of pregnancy, when the red cell count falls rapidly owing to the fact that two-thirds of the iron make-up of the foetus is then supplied. The blood count is typical of the microcytic form of anaemia described by Witts, in that the haemoglobin is diminished out of proportion to the red cell count, giving a low colour index, and in the absence of signs of haemolysis or rapid blood regeneration. Dyspepsia, dysphagia, soreness of the tongue, and enlargement of the spleen are all sometimes present.

\section{The Rarer Types}

The megalocytic type of anaemia of pregnancy is less c:ommon and appears to be due, as in true pernicious anaemia, to a break in the erythron at the level of the megaloblast. It differs from the latter only in the fact that achlorhydria is not a necessary accompaniment, and that the condition arises during pregnancy and is spontaneously relieved by parturition. The blood picture shows the usual high colour index and leucopenia, and cases generally react well to liver so long as neglect of treatment has not allowed them to fall into an aplastic phase.

There is no need to discuss here anaemia due to haemorrhage or haemolysis following haemolytic streptococcal or anaerobic infections, but a word may usefully be said about the acute idiopathic haemolytic anaemias, which are less rare during pregnancy but are probably related to the infrequently seen haemolytic anaemias occurring during other phases of life.

The symptoms of dyspnoea, oedema, syncope, transient amaurosis or paralysis, fever, haemorrhages, etc., are of sudden onset, usually becoming manifest in the latter two months of pregnancy, and are unaccompanied by any signs of infection or toxaemia. They may occur in primiparae or multiparae, they tend to recur in subsequent pregnancies, and the mortality is in the region of 30 per cent. The blood picture usually shows a megalocytic anaemia with active blood regeneration as evidenced by leucocytosis, and the presence of nucleated red cells ancl polychromasia. There is excessive haemolysis, causing a positive van den Bergh reaction, and the fragility of th: red cells is temporarily increased. Examination of the gastric contents may show no abnormality, but the liver and spleen are sometimes enlarged. The cause of the anaemia is unknown, and treatment consists of bloou transfusion, and, if the patient's condition warrants it, immediate induction of labour or Caesarean section. Liver treatment also seems to be of value in some cases.

\section{Recognition and Treatment of Microcytic Anaemia}

Although for the sake of completeness it has been necessary to mention the rarer types of anaemia of pregnancy it is the common microcytic type whose importance and frequency it is most necessary to realize. The onset is so insidious and the danger is so real if the patient be allowed to come into labour without previous treatment, that it would seem to make at least a haemoglobin estimation at the seventh month a reasonable routine precaution in ante-natal care. Moreover, the anaemia should be recognized early, as it is in this stage, before there is any tendency to aplasia, that a quick reaction to treatment is to be expected.

The best method of treatment is the administration of iron in large doses or liver, according to the microcytic or macrocytic nature of the anaemia, but the fact must not be lost sight of that both may be needed, and this is particularly obvious in the type of case in which there is originally a high colour index and under treatment with liver the cell count improves and the colour index falls, but the patient does not regain her full quota of red cells. In such a case a little iron will usually complete the recovery. If the patient reacts well to treatment the pregnancy should be allowed to go to term, but if the anaemia shows a tendency to aplasia then termination of the pregnancy must be considered whenever the patient appears to be in a fit condition to stand the shock of labour. In those cases in which severe anaemia is discovered only at term labour should be postponed as long as possible to allow of treatment, and, when it commences, Caesarean section with simultaneous transfusion probably affords the least risk of obstetrical shock.

\section{Four Illustrative Cases}

There are two points that it is particularly desired to stress: the frequency of a moderate degree of microcytic anaemia in pregnancy, and the consequent risk of obstetrical shock following delivery if the anaemia is not treated. These points, and also the insidious, occult nature of the anaemia, are well illustrated in the following case reports. 
Case 1.-This demonstrated the real risk of obstetric shock in a megalocytic anaemia of pregnancy. Mrs. C., aged 42, a multipara of five, gave a history that for three weeks before her last pregnancy, nine years ago, she had severe vomiting, and that she was very ill for some months afterwards. For five years she apparently had had a recurrent urinary infection. Within a month of again becoming pregnant she began to feel ill and vomited. She was admitted to hospital seven months pregnant in a very serious condition, very pale, and with oedema of the feet and abdomen. The urine contained no albumin, the blood pressure was 130 , and the blood urea was $22 \mathrm{mg}$. per cent. The blood count showed a haemoglobin of 30 per cent., red cells $1,300,000$, colour index 1.1, and white count of 6,000. A film showed slight anisocytosis and polychromasia and a few nucleated red cells. The patient was treated with liver extract, iron; and transfusion, but after a week she had but little improved. The urine now contained albumin, and the blood count was unaltered. Two days later the patient came into labour, which was rapid and normal in every way, and gave birth to a live child weighing $4 \mathrm{lb} .10 \mathrm{oz}$. The total blood loss was estimated at under $10 \mathrm{oz}$. The patient, however, became very shocked and died four hours later.

Case 2.- Some of the difficulties of diagnosis, even in a very severe grade of anaemia, were shown in this case. Mrs. G., aged 25, a multipara of three, was admitted to hospital, seven months pregnant, for toxaemia of pregnancy. She gave a history that for the past month she had felt tired, had had frequent headaches, and had lately begun to " swell up." On admission there was gross oedema of the legs, abdominal wall, and vulva. She was pale, but the pallor was masked by telangiectases on the cheeks. The blood pressure was $120 / 80$, temperature $99^{\circ}$, pulse $100-110$. The urine was of 1020 specific gravity, and contained a trace of albumin. Blood urea was $18 \mathrm{mg}$. per cent. Blood count: haemoglobin 22 per cent., red cells $2,120,000$, colour index $\mathbf{0 . 5}$, white cells 8,800. A film showed slight anisocytosis and few nucleated red cells. On treatment with massive doses of iron, within two weeks the patient felt quite well, all oedema had gone, and the haemoglobin was 50 per cent., with a colour index of $\mathbf{0 . 8}$. A test meal was performed and showed complete achlorhydria. The patient came into labour and.had a normal delivery at term, the blood count then beinghaemoglobin 80 per cent., red cells 4,000,000, colour index 1 .

Case 3.-A typical case of microcytic anaemia of moderate degree. Mrs. H., aged 29, a one-para, gave a history of vomiting and giddy attacks since seven - months pregnant. When seen at the eighth month a blood count showed a haemoglobin of 43 per cent., red cells $4,150,000$, colour index 0.5 , and white cells 4,600 . On iron medication the haemoglobin rose to 55 per cent. during the next month, and three weeks later, after a normal delivery, it had risen to 78 per cent.

Case 4.-Another case of moderate degree of microcytic anaemia. Mrs. T., a multipara of two, was seen when seven and a half months pregnant, complaining of paroxysmal tachycardia. On examination the heart appeared normal and the mucous membranes were slightly pale. A blood count showed a haemoglobin of 68 per cent., red cells $3,860,000$, colour index $\mathbf{0 . 8 8}$. On treatment with iron the haemoglobin rapidly rose to 79 per cent., the attacks ceased, and she had a normal delivery at term.

\section{BIBLIOGRAPHY}

Bland, P. B., Goldstein, L., and First, A.: Amer. Journ. Med. Sci., 1930, clxxix, 48 .

Hartfall, S. J.: British Medical Journal, 1934, i, 136.

Hugouneug, M. L.: Soc. Biol. Paris, 1899, li, 337.

Strauss, M. D., and Cástle, W. B.: Amer. Journ. Med. Sci., 1932 clxxxiv, 655

Whitby, L. E. H.: Journ. Obstet. and Gynaecol. British Empire, 1932, xxxix, 267

Witts, L. J.: Lancet, 1932, i, 653.

A conference on "Youth and Health: What can we do to Help?" organized by the British Red Cross Society, was held in London last June, and among the speakers were Dr. Ralph Crowley and Dr. Margaret Lowenfeld. A full report of the discussions has now been published by the society at 14. Grosvenor Crescent, S.W.1, in pamphlet form, price $6 \mathrm{~d}$.

\section{Clinical Memoranda}

\section{SUPERIOR MESENTERIC THROMBOSIS}

In connexion with an article on the above subject by Mr. R. M. Sargent, published in the Journal of July 14th (p. 64), it may be of interest to report a case of spontaneous recovery from a superior mesenteric thrombosis which occurred at the Herefordshire General Hospital under the care of Mr. E. W. Du Buisson, who kindly allows me to report it.

A woman, aged 54, was admitted in November, 1916, with abdominal pain and vomiting-pulse 120. An old right femoral hernia was reduced by taxis, and the patient, relieved, insisted on going home. The next morning she was sent. in by her doctor as a possible " reduction en masse" with acute abdominal pain and vomiting. The pulse was now 130. At operation the hernia was found properly reduced. The incision prolonged upwards, however, showed one and a half feet of small intestine near the caecum much dilated and rosy red in colour. There was lymph in the coils and a thrombosis of the mesenteric trunk. The contents were milked down, the hernial sac was removed, and peristalsis noted before the abdomen was closed. She recovered well, though enemata were necessary for some weeks.

Hereford.

B. E. W. Stallard.

\section{VARICELLA AND HERPES ZOSTER}

The cases described below, which would appear to show a clear clinical relation between herpes zoster and varicella, seem worthy of record. The Barbara-Edith Convalescent Home for Children at Blechingley is staffed by a matron and a nurse. There are, in addition, three domestics. Apart from these people and myself, as honorary medical officer, the twelve children, admitted there as convalescents from London hospitals and associations, come into contact with no other persons (except their parents, who are allowed to visit them on one day only in a month), since the home is right in the country and some way from any neighbouring dwelling.

Margaret W., aged $3 \frac{1}{2}$ years, was one of a batch of children admitted to the home on May 14th, 1934. She had, on the day of admission, her first crop of herpes zoster, localized to the tenth dorsal segment on the left side. Except for her age, her attack of shingles was in all respects completely typical, and was well developed when she was first seen by me on May 24th, ten days after its beginning.

Betty H., aged $3 \frac{1}{2}$ years, was one of the same batch 'of. children admitted on May 14th. On June 6th she developed a few vesicles, suspiciously like early varicella, but had nò fever. In the light of the other cases, and because of the subsequent course of her rash, there is no doubt that she hat an attack of varicella.

Poppy B., aged $4 \frac{1}{2}$ years, was also one of the same batch of children admitted to the home on May 14th. On June 7th - that is, on the twenty-fourth day following that of her admission-she developed a crop of vesicles in all respects like early varicella, and ran a temperature (up to $100^{\circ} \mathrm{F}$.) for forty-eight hours. By the third day there was no doubt that she had this disease. Since their admission the above three children had come into contact with no outside persons, except on a visiting day, which happened on June 2nd, and which therefore allowed too short a period of incubation for them to have been infected on that day.

On June 22nd Sadie G., aged $4 \frac{1}{2}$ years, was seen with typical first-day varicella. She had no doubt been infected by one of the two preceding cases.

Unless the varicella took at least twenty-four days in incubating, which is exceedingly improbable, there seems little doubt that it must have been communicated from the child suffering from herpes zoster, who was a free contact with all the other inmates of the home.

Blechingley. Douglas RoBertson, B.M., M.R.C.P. 